\title{
Museu de Artes e Ofícios, Belo Horizonte: afinal, como nascem os museus?
}

\author{
Belo Horizonte's Museum of Arts and Trades: after all, \\ how are museums born?
}

Entrevista com

Pierre Catel

Museólogo

Entrevista concedida a Luciana Sepúlveda Köptcke

Museu da Vida/Casa de

Oswaldo Cruz

Av. Brasil, 4.365

21040-900 Rio de Janeiro - RJ

Brasil

lsk@coc.fiocruz.br
CATEL, P.: Museu de Artes e Ofícios, Belo Horizonte: afinal, como nascem os museus? (Entrevista concedida a Luciana Sepúlveda Köptcke).

História, Ciências, Saúde - Manguinhos, v. 12 (suplemento), p. 323-38, 2005.

Responsável pela concepção do projeto do Museu de Artes e Ofícios de Belo Horizonte, o museólogo francês Pierre Catel discorre sobre sua experiência profissional, iniciada na década de 1970. Discute conceitos de museus, a evolução da formação neste campo multidisciplinar. Sobre o projeto de museu a ser montado no metrô da capital de Minas Gerais, ele diz que seu objetivo é promover o encontro entre a cultura das profissões e peças de uma coleção de arte popular brasileira com cerca de um milhão de pessoas a caminho de casa ou do trabalho.

PALAVRAS-CHAVE: Museu de Artes e Ofícios, Minas Gerais, Belo Horizonte, museologia, cultura, profissões.

CATEL, P.: Belo Horizonte's Museum of Arts and Trades: after all, how are museums born? (Interview by Luciana Sepúlveda Köptcke)

História, Ciências, Saúde - Manguinhos, v. 12 (supplement), p. 323-38, 2005.

Responsible for the concept behind Belo Horizonte's Museum of Arts and Trades project, the French museologist Pierre Catel talks about his professional experience, which began in the 1970s. He discusses museum concepts and the evolution and shaping of this multidisciplinary field. In regard to the museum that will be installed inside the subway of Minas Gerais' state capital, Catel says his aim is to foster an encounter between the culture of professions and pieces from a collection of popular Brazilian art, where around one million people pass by on their way to work or home.

KEYWORDS: Museum of Arts and Trades, Minas Gerais, Belo Horizonte, museology, culture, professions. 


\begin{abstract}
A cidade de Belo Horizonte abrigará em breve o Museu de Artes A e Ofícios, um projeto arrojado, reunindo um grupo imenso de profissionais de horizontes diversos, que brindarão os mineiros com um espaço cultural e educativo cravado no coração da capital, mais precisamente na Estação Central do metrô. Promover o encontro entre a cultura das profissões, com peças raras de uma belíssima coleção de arte popular brasileira e cerca de um milhão de usuários do metrô, no caminho cotidiano entre a casa e o trabalho, é a proposta de Ângela Gutierrez, empresária e empreendedora do mecenato cultural contemporâneo brasileiro. A proposta do Museu de Artes e Ofícios é debater as formas de organização da atividade produtiva em nosso país, discutindo como tecnologia, recursos naturais e contexto sociopolítico se mesclam, mas principalmente lembrar e celebrar gestos cotidianos da criação, que emanam do trabalho humano.
\end{abstract}

No dia 30 de outubro de 2002, fomos a Belo Horizonte conversar com o museólogo francês Pierre Catel, responsável pela condução deste projeto. Pierre Catel conhece bem o Brasil, onde já participou de outras iniciativas, inclusive com Ângela Gutierrez, como a implantação do Museu do Oratório, em Ouro Preto, e da reforma e desenvolvimento do projeto da Casa França-Brasil, no Rio de Janeiro, com Darcy Ribeiro.

Como nascem os museus? Por que continuam a nos fascinar em meio a tantas possibilidades e tecnologias culturais? Para quem são pensados, e quem os utiliza, efetivamente?

Durante quase três horas tentamos refazer o caminho entre a idéia, o projeto e o desejo que embasaram o nascimento do Museu de Artes e Ofícios, uma versão século XXI de processos que remontam ao berço do Humanismo, na Europa ocidental do século XVII.

Conhecer a genealogia e a trajetória dos diferentes museus contemporâneos, os desejos e os atores sociais que os tornam realidade, os critérios que presidem sua organização conceitual e museográfica, nos permite talvez compreender um pouco melhor a importância, a natureza e o futuro dessas instituições que, apesar de percebidas por alguns como depósitos elitistas de fragmentos culturais, têm demonstrado vitalidade e capacidade de adaptação ao participar, desde o século XVIII, de projetos de educação e divulgação da ciência, da consolidação da identidade nacional e da valorização da democracia, elementos estruturantes da implantação da modernidade no Ocidente. 
Na origem do projeto desse museu há milhares de peças que formam a coleção da sra. Gutierrez. Havia desde o início o projeto de se fazer esse museu?

Talvez o espírito mesmo do museu não estivesse definido na sua origem, quando Ângela começou suas coleções. Temos conjuntos que permitem apresentar uma profissão ou apresentar uma técnica de transformação e de fabricação. Conjuntos que são da mesma origem, que não são ajuntamentos de objetos espalhados, dispersos, mas que foram recuperados num contexto bem definido, e com as informações, também importantes, dos usuários dessa coleção. Com certeza, há peças que podemos chamar, digamos, mais unitárias, que voltaram à coleção pela sua raridade ou pela reunião de pessoas que propunham certas peças. Mas desde então vimos que o interesse era que pudéssemos fazer muitos museus. Essas coleções permitem fazer diferentes museus temáticos, permitem tomar uma posição essencialmente rural, local, essencialmente etnográfica. Portanto, vê-se bem que a coleção era elemento essencial para a origem do museu, mas que não era indispensável.

O senhor fala de conjunto homogêneo. De que são feitas essas coleções?

Essencialmente de arte popular, oriunda do meio rural. Acho que, na base, a origem foi lá. Em seguida, ela se desenvolveu com outros interesses e também com a tomada de consciência do desaparecimento de certos ofícios ou de certos objetos, que se tornaram muito raros. E a raridade, efetivamente, foi rapidamente percebida, uma vez que os objetos dos ofícios são levados a desaparecer pelo trabalho. Portanto, houve efetivamente essa percepção, e creio que a coleção pode ter-se ampliado nesse momento.

\section{O que definiu o tema, o projeto final do museu?}

O elemento indispensável, em seguida, foi a reflexão sobre a finalidade com a qual se fazia esse museu. Não era com a finalidade de conservação das coleções, uma vez que elas já estavam protegidas, mas com a finalidade, justamente, de difusão, de vulgarização de um conhecimento. Eu diria, de preferência, que foi isso. Nosso museu é, antes, um museu que mostra o know-how, a habilidade de uma sociedade, ao longo dos séculos, mas também com um certo cuidado ao mostrar esse know-how. Como integrar essa habilidade e como lhe dar uma permanência em nosso mundo contemporâneo? Se você quer saber, o importante é que, com uma coleção que se poderia chamar de arte popular há trinta anos, poderíamos fazer um museu de arte popular muito simpático, bem caloroso, convivente, com belos objetos e tudo, mostrando como mamãe fazia doces, como papai ia ganhar o pão, mostrando de fato essa sociedade tradicional, desabrochada, um pouco paternalista mesmo. Bem, não foi nada disso o que fizemos. Nós nos demos conta de que 
estamos na aurora do século XXI, mas ainda com um pé no século $\mathrm{XX}$, e nos demos conta também de que talvez fosse preciso parar com essa imagem dessa sociedade tradicional, que se arrasta no tempo e que olhamos com emoção. Ao contrário, sentimos bem que a realidade não é essa; que a realidade é muito mais dar uma identidade para o trabalho, valorizar a qualidade profissional, restituir uma forma de identidade às pessoas que trabalham manualmente e hoje são pouco respeitadas na nossa sociedade tão avançada tecnologicamente. Hoje ainda há lugar para um artesanato de qualidade, que está prestes a se perder na nossa sociedade ocidental. E o que eu digo se aplica para a França e para o Brasil. Hoje, nos demos conta de que um marroquineiro, um seleiro, pessoas que trabalham com o couro e têm perfeito conhecimento de seu trabalho, têm uma grande capacidade inventiva nesse trabalho, são mais procurados - e raros - no mercado de trabalho do que um técnico em informática. Portanto, talvez o dever desse museu, com essa coleção, seja mais de redinamizar, de fato, essa imagem de qualidade do trabalho do artesão e da manufatura.

\section{O museu foi pensado para um publico em particular?}

Nosso objetivo era ter um público bem popular, uma vez que íamos trabalhar num terreno para difundir um conhecimento popular, e era preciso restituir uma identidade, um interesse ao trabalho manual e ao trabalho técnico. Aliás, era preciso se situar num lugar onde o público já estivesse antes. Foi por isso que pensamos na possibilidade de fazer esse museu numa estação de metrô. Agora, se vamos falar em percentagem, não serei capaz de dar percentagens, mas, digamos, podemos pensar em um milhão de usuários do metrô. É evidente que aqueles que queremos atingir é o público da periferia urbana, que não tem, forçosamente, muitos espaços culturais à disposição. São pessoas que, nós sabemos, estão cansadas à noite, quando voltam do trabalho. Se queremos que eles venham ao museu por um tempo, é preciso atraí-los, mas não com grandes teorias. Em compensação, sabemos que é um espaço facilmente acessível para eles, porque há o metrô. Por outro lado, nossa atividade com o público é bem objetiva, e com certeza há atividades que serão feitas na estação, e até mesmo dentro do metrô. Temos também projetos de trabalhar com apresentações nas outras estações ao longo da linha. Há muito o que fazer lá dentro e vimos que os pesquisadores nos seguiram - e não apenas nos seguiram: eles já nos ultrapassaram. Chegando a uma estação de metrô, eu poderia fazer isso, aquilo etc. Mas ainda não se começou, mesmo havendo tantas estações. Portanto, desde então a idéia avança. Agora, é verdade que o público foi atraído, convidado. Os industriais estão interessados; isto quer dizer que eles participarão dos eventos, desse espaço temporário dos acontecimentos. Portan- 
to, já temos a oportunidade de fazer contatos e propostas, pois esse é um museu por si mesmo aberto aos outros. E este era, sobretudo, o objetivo.

Há outras experiências como essa em algum outro lugar?

Eu sei que nesse momento, em Bruxelas, na Estação Central, há um Museu do Transporte. Um Museu do Transporte dentro de uma estação parece inteiramente normal e sem ambigüidades. Mas museus temáticos, que nada têm a ver com os transportes, que sejam feitos nas estações, creio que esse nosso é o primeiro. Em compensação, exposições, sim, já houve antes. Há grandes espaços públicos utilizados para exposições já há muito tempo. Na Europa, em Paris, por exemplo, no metrô em Châtelet, passam cinco milhões de pessoas por dia. É um lugar onde há permanentemente exposições temáticas em todos os campos: campos inovadores, assuntos de ciências, campos de conhecimentos técnicos etc. Portanto, isso já se faz. Mas um museu, um espaço instalado permanentemente dentro de uma estação, creio que é a primeira vez, igualmente com dificuldades, dificuldades do metrô, de segurança etc. Quero dizer também que outro aspecto muito importante é o aspecto urbanista, porque atrás desse projeto redinamizamos um espaço que foi abandonado pela cidade. Essa foi uma experiência que eu já havia feito no Brasil, no Rio de Janeiro, quando Darcy Ribeiro me chamou para fazer a Casa França-Brasil.

Na época, início dos anos 1980, quando começamos a Casa França-Brasil, eu estive no lugar, e encontrei um espaço bastante abandonado, casas destruídas ou mais conservadas, e a Bolsa de Comércio, que fora um Palácio da Justiça, se tornara um estacionamento, com os Correios ao lado. E me lembro da frase de Darcy Ribeiro, porque eu lhe disse: "Você sabe, Darcy, penso que a França não quer pagar por esse projeto. Ela não está muito interessada”. Ele disse: "Mas para mim dá no mesmo, que o projeto saia ou não saia. O que é importante é conscientizar os cariocas de que se pode salvar o Centro da cidade, e que é preciso redinamizá-lo. Estamos, portanto, Pierre, usando a Casa França-Brasil para fazer o carioca redescobrir o interesse neste centro histórico do Rio de Janeiro". E agora, vinte anos mais tarde, estamos fazendo o mesmo em Belo Horizonte. Mal começamos a colocar um andaime, que já se vê; começamos a pintar a casa de novo, o que já se vê; começamos a ver como vai ficar. Portanto, essa é a oportunidade que se apresentou, mas é verdade que, no sentido do urbanismo, freqüentemente temos zonas que estão esquecidas, e achamos que o melhor a fazer é destruir, apagar, fazer outra coisa no lugar. Mas não; o melhor é saber usar o que existe para redinamizá-lo e encontrar uma idéia que o faça funcionar de novo. 
Como a política de aquisição definida para o museu articula os objetivos da popularização com a pesquisa?

O museu por si foi concebido para não ser estático. Foi concebido para ser não vou dizer evolutivo porque a palavra é simplista, mas foi concebido para ser posto de novo em evidência. Eu acho que é sobretudo isso. Percebemos bem que não se poderia definir verdadeiramente o que seria essencial no museu. Portanto, o que definimos como essencial foi a possibilidade de colocá-lo de novo em questão, seja em nível universitário (o modo como os temas são abordados), seja simplesmente pelas coleções que podem surgir, que hoje já não existem mais. Por isso, fizemos ainda as galerias temáticas do museu e vamos levantar um edifício que será uma reserva aberta ao público, que fará parte da visita ao museu, como os laboratórios. E isto para mostrar melhor que podemos fazer em reserva aberta esses campos de experiência, antes de colocá-los nas galerias. Por outro lado, faremos também um edifício para a formação profissional. Esta formação profissional é construída em torno de uma idéia simples, que quer dizer: é importante ter uma formação pedagógica, para as crianças.

Resolvidos o tema e a localização desse museu, aumentamos, em compensação, a área para a formação profissional, que vai ser útil para quem trabalha com madeira, pedra, ferro etc., e esses cursos e encontros entre profissionais se farão com professores, tanto os professores universitários de tecnologia, técnicos, quanto os profissionais do ofício, mas também artistas contemporâneos, para termos sempre uma dimensão mais ampla do que a da especialização da profissão. Queremos mostrar as capacidades e a dimensão do know-how em cada uma dessas profissões. Trabalhamos com universitários também, tanto de universidades de São Paulo como de Belo Horizonte e do Rio de Janeiro. Vários, muitos - perto de cinqüenta universitários - trabalham conosco precisamente em assuntos relativos ao projeto.

Pode-se dizer que o Museu de Artes e Ofícios privilegiou uma narrativa sócio-histórica do trabalho artesanal. Seria possível abordar o projeto através do olhar de uma história das técnicas?

Quando trabalhamos com historiadores sobre o projeto, no campo das técnicas e do trabalho, fomos sempre confrontados com uma imagem histórica do Brasil e da história da escravidão. De modo que nos demos conta também de que, se de fato escolhêssemos essa fase, essa trama histórica do trabalho, faríamos de novo um museu que já existia, que existe hoje ainda, que ainda se fará um dia. Então nós partimos de uma outra idéia. Primeiro, nos dirigimos a um público de brasileiros, que têm cada um suas origens - graves, terríveis: escravidão, imigração etc. Esse aporte de origens diferentes e de conhecimentos não apenas culturais, mas que remontam aos 
indígenas, talvez fizesse o diferencial desse museu. Essa particularidade nos permitiu fazer uma distinção sistemática em relação a essas técnicas, com a condição de demonstrar que, quaisquer que sejam as condições, temos conhecimentos que se trocam. E é isto que faz essa originalidade brasileira - como na Europa houve a influência dos bárbaros, dos hunos, dos visigodos etc. Mas é verdade que quando se produz um utensílio não se vai procurar a origem; tentamos compreendê-lo melhor.

Portanto, temos um museu que se construiu sobre demonstrações da evolução das técnicas, efetivamente: a energia humana, a energia animal, a energia hidráulica, a energia elétrica - e em cada uma delas, historicamente, talvez possamos explicar melhor por que a escravidão desapareceu. Não foi apenas uma forma de pensar, mas foram também as origens da evolução técnica que permitiram descobrir que não tínhamos mais necessidade de escravos. Não quisemos esconder isso. Mas o que quisemos mostrar, sobretudo, é que o lado positivista do progresso se demonstra todos os dias, e que é por causa desse progresso, efetivamente, que temos comportamentos diferentes, também sociologicamente.

\section{Quais são as outras abordagens temáticas?}

A outra galeria, de fato, é uma galeria que está relacionada com o nosso espaço, com a história do hemisfério Sul, que é o problema do transporte. Associamos finalmente todas as profissões ligadas ao transporte. O transporte, hoje, é algo muito importante na economia e é a parte mais visível da tecnologia contemporânea, que apresenta problemas visíveis, como a poluição. Portanto, e ao mesmo tempo, talvez esta seja também a técnica mais importante na origem do Brasil. É a navegação, o transporte. O Brasil é descendente de uma história do transporte. Portanto, não quisemos começar por outros aspectos, como as pessoas que trabalham e que vivem do transporte, ou em torno do transporte... Isso vai até as profissões dos ambulantes, dos barbeiros ambulantes até as pessoas que atendem na rua, pessoas que dão de comer, e depois os que trabalham para fazer rodas, carroças etc. Essa noção, essa galeria se amplia justamente com o comércio e os profissionais do comércio.

Temos uma outra galeria, que é a galeria da região das matériasprimas do Brasil. A idéia é apresentar todas as matérias-primas brasileiras, e apresentá-las, de fato, assim: duas caixas-pretas; uma sobre essa sociedade tradicional da fazenda - a construção sociológica e técnica em volta da fazenda; de outro lado, a construção, com as paredes, de uma sociedade pré-industrial e que politicamente vai começar a mudar. Foi em seguida que descobrimos a galeria da energia. Um quarto aspecto que foi protegido e privilegiado, e que é também atemporal e permanente, será o da alimentação. De início, uma técnica feminina, mas em seguida vimos essa evolução, 


\footnotetext{
1 Os museus de sociedade, ou ecomuseus, termo criado por George Henri Rivière e Hugue de Varines em 1971, designam um tipo de museu que visa a relacionar, criar sinergias, entre as coleções e o meio ou contexto onde estas se inserem (Caillet, 1995). François Hubert diz que não são os objetos que se acham no centro das preocupações do museu de sociedade, mas sim o sujeito social. A memória coletiva torna-se o principal patrimônio (Hubert, F., apud Desvallées, 1994).
}

digamos, do pão à padaria industrial. Mas vimos sobretudo, de fato, todas as técnicas de know-how, tanto para se alimentar qualquer que seja o contexto, a inteligência do Homem posta em ação - como para se vestir, que também é uma forma que, geograficamente, recupera aparências e interesses diferentes.

O senhor saberia definir esse museu? O senhor fala dele, mas poderia apresentá-lo de forma mais sintética?

Bem, eu diria que ele se enquadra como um museu de sociedade, ${ }^{1}$ que com certeza é um instrumento tão amplo que todo mundo se enquadra nele. Mas nós não nos fizemos essa pergunta. Não procuramos dar uma categoria ao museu, catalogá-lo. Creio que ele vá se definir por si mesmo, no andamento, na seqüência, e diria que ele não foi trabalhado como um museu de sociedade, mas sim como um espaço de sociedade. Eu o sinto mais assim. É um espaço, um encontro entre uma sociedade contemporânea, um pouco e até muito perturbada, justamente a respeito dessas qualidades profissionais. Temos dúvidas, porque não há uma garantia muito forte na nossa tecnologia para esse formato que escolhemos. Colocamos um pouco em discussão muitas coisas. Às vezes olhamos para o passado com um olhar muito brando. O passado não foi mais feliz que isso, e penso que esse museu é mais um espaço de encontro entre dois mundos, que é o nosso mundo. Aí está. Por isso, de fato: é mais pela atividade de implantação que pensamos que esse museu terá forte identidade neste país, mais que pela sua coleção e pelo edifício, essencialmente. Não é mesmo assim que se vai interagir. Além do que eu diria que alguma coisa, para o público dos museus clássicos, ficará talvez um pouco confusa, porque em vez de um audiovisual sobre os assuntos, temos um trem que passa no meio do museu, que se depara com os minérios, com o mármore, com o granito, e isso vale por um audiovisual gigante, quando você tem o barulho, quatrocentos vagões que passam pelo meio do museu. Portanto, não estamos mais dentro daquela forma: onde está a etiqueta, para ler a referência? A referência passa diante de você. Ela vive diante de você. É essa noção do que é vivo, porque fomos postos junto aos vivos! Não se procurou retirar esse espaço museográfico do mundo cotidiano, do permanente. E um milhão de pessoas vão passar, tomar o metrô, por ano - os trens de mineração que atravessam o museu. É evidente que temos a mesma noção, não procuramos mesmo fazer um museu com pequenas etiquetas. Haverá, tranqüilizamos as pessoas; mas de fato trabalhamos com uma outra dimensão que está no lugar de fazer maquetes. Estamos na dimensão da escala 1:1. Aí está! 

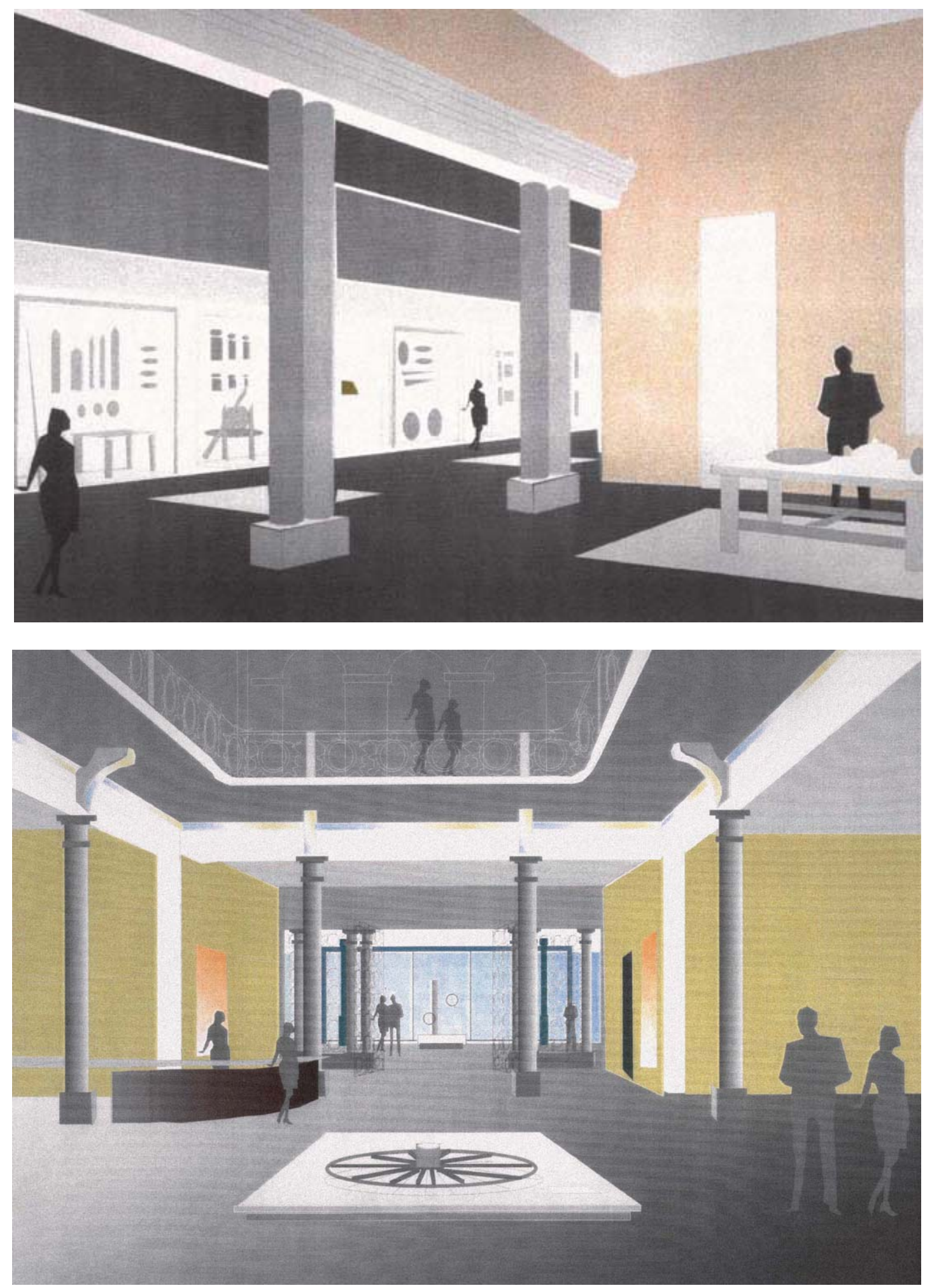

Croquis das salas de exposição do Museu de Artes e Ofícios de Belo Horizonte. 
PIERRE CATEL
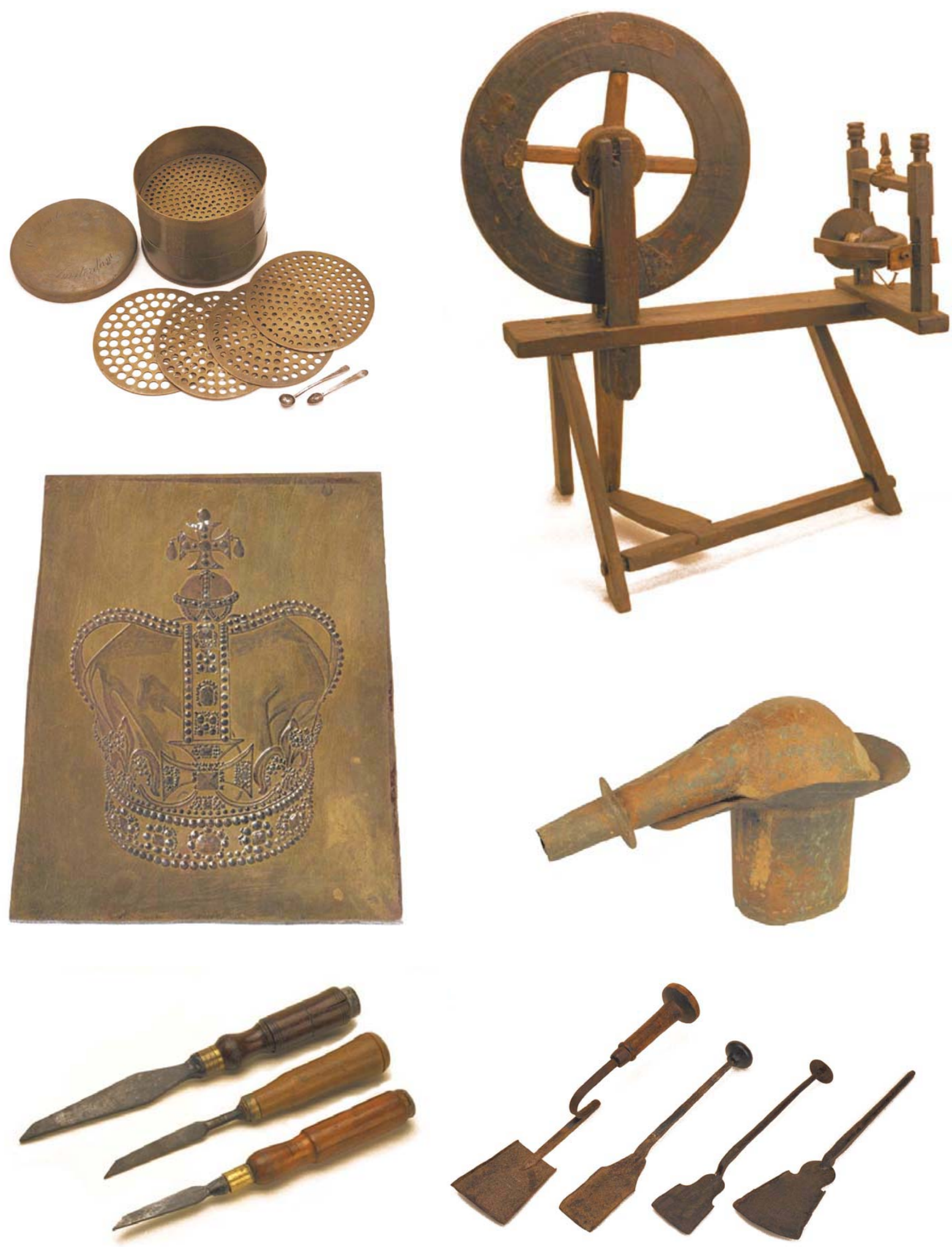

Peças da coleção de arte popular que devem integrar a exposição do Museu de Artes e Ofícios de Belo Horizonte. 

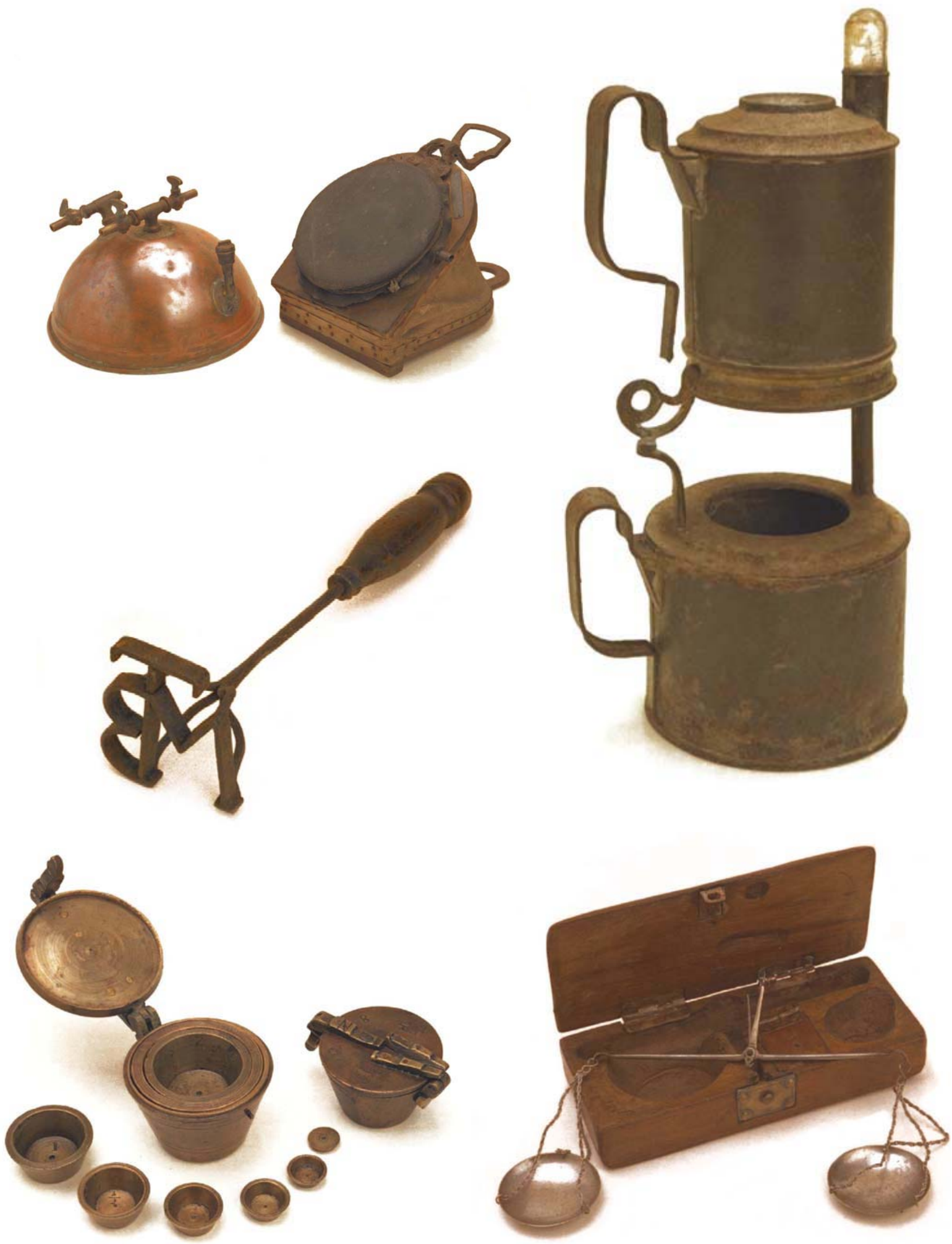
Muitas vezes temos tentativas, e elas são muitas por todo o mundo, de democratizar os museus, e fazer deles uma experiência ao alcance da maioria. Quais são, na sua opinião, as experiências e os enfoques que conseguiram despertar interesse e fazer vir pessoas que, por hábito, não vinham ao museu?

Penso que olhando para trás podemos ver que, nos últimos trinta anos, os museus que são os mais visitados, que têm mais audiência entre o grande público, são sempre, apesar de tudo, os museus que optaram por sair do classicismo rigoroso. Na arte contemporânea, quando eu vejo o Beaubourg... Eu mesmo, quando vi o Beaubourg quando era pequeno, quando era jovem, não fiquei encantado ao ver uma construção como aquela bem no meio do Marais; aliás, de fato, eu fiquei magoado pelo que se passou no Halles, terem partido o centro de Paris etc. Rapidamente reconheci que o Beaubourg foi um êxito como a ferramenta cultural que é hoje, que excede mesmo, já que fomos obrigados a refazê-lo praticamente todo, de tal modo ele sofreu. E, digamos, ele sofreu de prazer, ele sofreu de trabalho, mas não sofreu de abandono. Este é um belo sofrimento.

Quando eu vejo como foi desaprovada a Pirâmide do Louvre, sistematicamente recusada... Hoje, tornou-se a prova da capacidade de funcionamento de um estabelecimento que era pesado e difícil de visitar para o público em geral. Hoje a reorganização é feita assim: a Pirâmide está ancorada no metrô, no comércio etc., quer dizer: toda vez que nos integramos à vida cotidiana, isso funciona. Isso não é de hoje; apesar de tudo, faz poucos anos.

Quando eu vejo a Villette, que tem um museu que não é um museu, que é uma cidade das ciências, portanto não é uma coleção, mas são objetos para usar... Quando vejo que a população vem passar um tempo, vem se impregnar, vem se reunir através da cidade da Villette! Acabei de fazer em Paris um museu que se chama Museu das Artes Forasteiras, que fica aberto à noite, que só abre quando fazemos festas. Quer dizer: há cuspidores de fogo; podemos fumar, podemos beber etc. Bem, percebemos que há 250 mil visitantes por ano, já que se não fosse por esse sistema, seriam 10 mil. A cada vez damos ao público a possibilidade de se apropriar do museu e não visitar o museu dos outros, e de se apropriar do museu a cada vez de um jeito. A inovação: lá está ela! Trata-se de encontrar a idéia de como as pessoas podem se apropriar: pode ser pela pedagogia, pode ser por meio de cursos, pode ser através de festas, mas pode ser também para espaços de reunião. E assim podem abrigar casamentos também, ou uma primeira comunhão, não sei. De imediato as pessoas se apropriaram do lugar e o lugar tornou-se delas. E assim, efetivamente, deu certo! Tanto que esse museu permanecerá num lugar diferente do cotidiano, um lugar onde se vai de tempos em tempos, e para fazer determinadas coisas. Ir ao museu permanece um ritual. 
Quer dizer que temos sempre uma expectativa muito conservadora em relação ao modo pelo qual as pessoas devem se apropriar dos museus. Não fazemos esforços; há facilidade de fato. Neste caso, o senhor crê que os estudos de avaliação podem ser úteis?

Estudos de avaliação: apesar de tudo, eu os deixo para os que refletem sobre o fluxo das viaturas, e coisas que se organizem como os sinais vermelhos, as encruzilhadas. Creio que, em nosso meio, a avaliaçãonos serve para compreender onde está o nosso público. Onde está o público? Há que encontrá-lo, procurá-lo. Mas a avaliação raramente me trouxe algo que me levasse a uma idéia.

Então há um criador no momento da concepção do espaço, da exposição? De todo modo há uma criação. Há qualquer coisa da ordem da criação, como para a arte, também para a ciência?

O museu não é uma ciência; é como a medicina. Não são ciências; são técnicas, mas é sobretudo arte. A arte da medicina. Eu acho que é a arte dos museus! Fizemos escolas; ótimo. Há universidades de medicina; apesar de tudo, há certos médicos que demonstram ter uma intuição além do conhecimento, ou graças ao conhecimento! Enfim, pela intuição chegam a encontrar uma vacina que os outros não encontram. Claro que há o risco, porque a arte é risco! E para mim, um museu sem riscos... assim é ruim viver.

No tex to de apresentação do projeto se diz que este poderia ser um centro de vulgarização de conhecimentos em museologia. Na sua opinião, como evoluiu a formação e qual é o perfil do profissional no meio museal?

O museu tornou-se hoje uma tal empresa que é, de fato, mais que um departamento. É praticamente um estabelecimento com múltiplas atividades, portanto múltiplos perfis de competência. E penso que isto irá adiante, vê-se bem que o museu se organiza como uma sociedade, que deve responder a demandas. Não gosto de dizer de uma clientela porque este não é o meu espírito, mas uma demanda de público, que é muito variada, que muda muito, e que não é, necessariamente, exatamente pedagógica, ou essencialmente, ou somente pedagógica. Mas ela é também, sobretudo, toda uma variedade de demandas possíveis e imagináveis. Por outro lado, um museu, na sua forma de vulgarização e de difusão, suscita um espaço de sociabilidade, que convoca outros especialistas; percebemos, de uma só vez, que não há mais um perfil exato: há um excelente gerente à frente de tudo e há um espírito de equipe muito bom dentro do museu.

Fale de si, do seu percurso, de seu encontro com o museu...

Aprendi os primeiros passos de Museografia com Georges Henri Rivière, entre os anos 1968-1974; ou seja, participei como um jovem aprendiz neste museu que era o Museu Nacional das Artes e 
Tradições Populares. Trabalhei lá 14 anos e o deixei, porque ao fim de 14 anos senti que havia pouca evolução possível ali. Estava preso ao testamento de Rivière, no qual não podíamos mexer muito, $\mathrm{e}$ que fazia com que eu não me sentisse mais guardião desse testamento. Talvez guardião do museu, mas não do testamento. E ainda assim eu estava pronto para levar adiante as idéias de Rivière em outros domínios, em outros campos e em outras experiências. Portanto, montei minha própria Sociedade de Museografia. E da museografia fomos chamados para trabalhar em diferentes campos, em outros países, regiões diversas, ao mesmo tempo sobre a programação, a concepção, a realização, com os arquitetos, com as diferentes equipes de arquitetos, com diretores de pesquisas, pessoas de diferentes especialidades. E isto me permitiu participar da realização de mais de quarenta museus no mundo todo, e cento e cinqüenta, duzentas, trezentas exposições.

O senhor trabalhou com Rivière. Como o senhor vê os projetos de ecomuseus? Pode-se chamar isto de uma utopia?

$\mathrm{Na}$ época não foi uma utopia, foram realidades! O museu de Camargue; este eu o presumi, foi um ecomuseu muito enriquecedor em experiências, justamente no nível das comunidades, já que os camarguenses de origem não estavam interessados no museu. Mas foram os novos imigrados, recém-instalados na região, que trabalharam muito na elaboração, no resultado das pesquisas, na coleta de informações na região da Camargue.

Para dar um exemplo bem perto de vocês: eu vi, sei que agora se trabalha muito nas comunidades italianas no Brasil. Encontro freqüentemente libaneses, brasileiros de origem libanesa, de origem italiana. Eu diria que de fato essas comunidades estão mais preocupadas com o patrimônio e a identidade brasileira do que brasileiros descendentes, depois de três ou quatro séculos. Por quê? Porque eles ainda estão preocupados, mesmo se são uma, duas ou três gerações; conservam ainda um sentimento de ter feito uma escolha na vida, de vir para o Brasil, com as utopias na cabeça, só com o que era preciso, saindo de um contexto que não os satisfazia - por exemplo, a Primeira e a Segunda Guerras Mundiais. Portanto, eles têm sede de se integrar culturalmente e de ser reconhecidos dentro desse patrimônio. De modo nenhum é uma utopia: é uma realidade. Em compensação, freqüentemente, essas atitudes, esses gestos são um pouco esquecidos ou mal-interpretados; interpretados como pessoas que querem formar uma comunidade. Eu acho que não, sobretudo no Brasil. Acho que é antes uma necessidade de integração no patrimônio e na identidade do país. Portanto, não é mesmo uma utopia de Rivière; foi uma visão dos anos 1970. Hoje temos uma nova visão, e amanhã ela será ainda surpreendente. Porque, quando se vê, com o mundo muçulmano, a dificuldade 
que se tem entre a cultura democrática anglo-saxã e a cultura democrática latina, na qual não temos a mesma noção de integração... O museu é um lugar onde se pode ressaltar este tipo de questão, e podemos responder a ela de modo diverso daquele do discurso politicamente correto. Veja você: estamos longe de ser uma utopia. Penso que isto se torna cada vez mais indispensável.

\section{REFERÊNCIAS BIBLIOGRÁFICAS}

Caillet, E. 1995

Desvallées, A.

1994
À l'approche du musée, la médiation culturelle. Collection Muséologies, Lyon, Presses Universitaires de Lyon.

Vagues: une anthologie de la nouvelle muséologie.

Tome II, Mâcon, Éd. W/M.N.E.S. 